\title{
Design and implementation of a survey quantifying winter housing and bedding types used on Vermont organic dairy farms
}

\author{
Tucker Andrews, ${ }^{1} \oplus$ Caitlin E. Jeffrey, ${ }^{2} \odot$ Rachel E. Gilker, ${ }^{3} \odot$ Deborah A. Neher, ${ }^{1}{ }^{\oplus}$ and John W. Barlow ${ }^{2 *} \odot$ \\ ${ }^{1}$ Department of Plant and Soil Science, University of Vermont, Burlington 05405 \\ ${ }^{2}$ Department of Animal and Veterinary Sciences, University of Vermont, Burlington 05405 \\ ${ }^{3}$ CSR Consulting, North New Portland, ME 04961
}

\begin{abstract}
We conducted a descriptive observational study to quantify the frequency and diversity of winter housing and bedding types used by organic dairy farmers in Vermont. This report describes the survey methods, results, successes, limitations, and lessons learned from administering the survey. Beginning in December 2018, a short questionnaire was administered by web, mail, and telephone to a source population defined as all producers of organic dairy cow milk in Vermont $(\mathrm{n}=177)$ listed in the United States Department of Agriculture Organic Integrity database. Our approach yielded an $82 \%(\mathrm{n}=145)$ response from certified organic farms producing cow milk in Vermont at the time of the survey. The 3 most common housing and bedding material combinations used by respondents were tiestall housing with wood (sawdust or shavings) bedding materials (45\%), freestall housing with wood bedding materials $(14 \%)$, and freestall housing with sand bedding (12\%). Fifteen percent of respondents reported using more than one type of facility for winter housing of lactating cattle. The median number of lactating cows on farms among respondents was 59.5 (range: 2-400), and the odds of using more than one type of facility to house lactating cows increased positively with the number of lactating cows reported for a herd. Breed distribution was similar across the housing and bedding type categories. An association between frequency of individual cow milk somatic cell count testing and housing type was identified; respondents using freestall sand facilities tested less frequently than respondents using tiestalls with wood bedding. Although the questionnaire length limited the amount of information gathered, the response proportion was exceptional, and overall our survey results provide valuable insight on Vermont organic dairy housing and bedding practices that should inform
\end{abstract}

Received October 26, 2020.

Accepted March 6, 2021.

*Corresponding author: john.barlow@uvm.edu future extension and outreach efforts for this sector of the dairy industry.

Key words: cattle, organic farm, dairy, survey, animal housing

\section{INTRODUCTION}

Dairy cattle housing and bedding systems influence animal health, reproduction, milk quality, animal wellbeing, productivity, and farm profitability (Bewley et al., 2017). Future trends of dairy cattle housing will reflect consumer demands, animal behavior, and environmental impact (Bewley et al., 2017). The longterm sustainability of the dairy industry depends on the extent that housing systems reflect these priorities (Beaver et al., 2020). In 2014, tiestall housing systems were the most common housing types for lactating cows among all dairy operations in the United States and foremost among operations with fewer than 100 cows (USDA, 2016). Tiestall or stanchion barns were reported as the milking facility for $51 \%$ of organic farms in New York, Oregon, and Wisconsin (Stiglbauer et al., 2013). Regional differences in herd size and types of facilities exist among US dairy operations (USDA, 2016), and it is unclear how Vermont organic dairy farms compare with other northern-tier US states that lead in organic dairy production (O'Hara and Parsons, 2013; Richert et al., 2013). Vermont ranks sixth by number of certified organic dairy farms per state and first by number of certified organic dairies per square mile in the United States (USDA-NASS, 2017). In 2019, the number of certified organic dairy farms was $177,26 \%$ of the total 675 cow dairy farms in the state.

Organic production regulations in the United States stipulate that living conditions provide "year-round access for all animals to the outdoors, shade, shelter, exercise areas, fresh air, clean water for drinking, and direct sunlight, suitable to the species, its stage of life, the climate, and the environment" and pasture access providing "a minimum of 30 percent of a ruminant's dry matter intake, on average, over the course of the grazing season(s)" (USDA, 2020). Under these regu- 
lations, temporary confinement or shelter is allowed because of inclement weather or conditions that could jeopardize the animals' health, safety, or well-being. In the northern United States, including Vermont, where inclement weather and heavy snowfall may dominate during winter months and pasture access may be limited from November to March or April, organic dairy herds may be housed indoors for extended time periods. Animal welfare, health, and productivity measures appear to be influenced by both type of bedding material and facility (Leso et al., 2020). The conditions in which organic dairy cows are housed during these months of inclement weather or when pasture is unavailable may influence cattle health, well-being, and productivity. It is currently unclear how animal health and productivity outcomes such as hygiene, mastitis, and milk production and quality differ among freestalls, tiestalls, and compost bedded pack facilities (Leso et al., 2020).

Reported frequencies of milking facility types (e.g., parlor vs. tiestall or stanchion milking) on organic dairy farms in other northern US states may provide a crude estimate of the corresponding housing facilities but do not provide specific estimates of winter housing or bedding materials (Stiglbauer et al., 2013; Sorge et al., 2016). For example, pasture or dry-lot was designated as the primary housing type (110 of 192 farms) for lactating cows on organic farms in New York, Oregon, and Wisconsin (Richert et al., 2013). Because only $22 \%$ of farm visits were conducted in the winter for this survey, it is possible that seasonality of the survey biased the primary housing type reported. Further, these prior surveys did not appear to capture the type of bedding material used, and some styles of housing (e.g., looseor open-housing pack barns) appear to be reported infrequently. Although it is unclear how many US organic dairy farms have adopted bedded pack loose-housing systems for lactating cattle, non-freestall loose housing is on the rise. Between 2007 and 2014, non-freestall loose housing increased from $3.4 \%$ to $6.4 \%$ of all dairy facilities and from $3.5 \%$ to $8.5 \%$ of facilities for dairies with a herd size of fewer than 100 cows (USDA, 2010, 2016).

In Vermont and nationally, extension publications have promoted the construction and use of bedded pack or compost bedded pack facilities as an alternative to traditional housing systems (Bewley et al., 2012; Gilker et al., 2012; Ogejo, 2018; Endres and Janni, 2019). However, a paucity of information on the distribution and types of bedding materials used on organic dairy farms nationally or regionally in the United States makes it a challenge to properly design and conduct observational studies to identify associations between housing systems and productivity or health and welfare outcomes. The primary objective of this descriptive study was to gain a reliable estimate of the frequency of housing and bedding material types used on organic dairy farms in Vermont, specifically aiming to quantify the number of producers using a bedded pack or other loose-housing systems. Due to a small target population, confidence in our results depended on a high response rate. To address this challenge, we designed and implemented a short-format questionnaire that was administered by multiple methods with 2 follow-up communications. Therefore, a secondary objective of this work was to report on the methods we applied in an attempt to achieve a response from at least $40 \%$ of the source population. Additional factors addressed in this survey were years of farming experience, herd size, breed(s) of cattle, and the frequency of use of individual cow SCC testing through DHI providers among farmers using different housing and bedding types. This report discusses both methodology of administration and results of the Vermont Organic Dairy Winter Housing and Bedding Survey.

\section{MATERIALS AND METHODS}

With input from social scientists, a survey tool was developed to estimate the frequency of different housing and bedding types used on organic dairy farms in Vermont in the winter of 2019. The survey tool was a short questionnaire designed to be administered by multiple methods (mail, internet, telephone). The process included initial outreach, survey distribution through online access and mailed paper copies, and follow-up mailings and telephone reminders with the opportunity to complete the questionnaire by telephone interview. Survey methodology was approved by the institutional review board at the University of Vermont (CHRBSS: 19-0057), and respondents received no reimbursement for completion of the survey. The Strengthening the Reporting of Observational Studies in Epidemiology statement checklist for veterinary medicine (STROBEVet; O'Connor et al., 2016) was considered during survey design and for reporting results.

\section{Sampling Method}

The target population was organic dairy farms in Vermont, with possible relevance to organic dairy farms in the northeastern United States. The source population was farms in Vermont that were producing and shipping certified organic cow milk at the time of the survey. We hypothesized that bedded pack systems would be used less frequently compared with tiestall or freestall housing systems. Sustainable agriculture extension experts provided estimates that approximately 30 dairy farms used bedded pack systems in Vermont, 
with the majority being used on organic dairy farms. Therefore, the target number of survey respondents was at least 82 organic dairy farmers, based on an a priori estimate of $20(10 \%)$ organic dairy farmers using bedded pack systems in a fixed population of approximately 200 organic dairy farms, an allowable margin of error of $5 \%$, and assuming type I error of $5 \%\left(\mathrm{Z}_{\alpha}=\right.$ 1.96).

Obtaining contact information for farmer populations can be a challenge because state agriculture agencies may not share dairy farmer contact information and because farmer populations may be dynamic. For example, the number of organic dairies in Vermont identified in state government data increased from 184 in 2015 to 203 in 2016 and then declined to 190 by the first quarter of 2019 (Bothfeld, 2020), although the list of individual farms is not freely accessible through state agencies. In comparison, the USDA Organic Integrity (USDA-OI) database (https://organic.ams.usda.gov/ integrity/) is publicly accessible; the data are provided by USDA-accredited certifying agents (certifiers), and databases are updated by certifiers monthly or more frequently. Dairy farm names and addresses were retrieved from the database using the terms "dairy cow: milk" and "VT-Vermont." Two searches were performed. First, a search of the USDA-OI database conducted on October 10, 2018, yielded 197 farms. At the time of our initial USDA-OI database search, it was unclear when the database had last been updated. A second search of the same database on January 10, 2019, reflected an update in December 2018, yielding a smaller pool of 177 farms. Contact information from the first search was used for the mailing list for the initial questionnaire, and information from the second search of the updated database served as a reference for verification and defined the source population of certified organic dairy farms producing milk in Vermont for this study.

\section{Questionnaire Design}

The survey tool was designed to be administered as a mailed questionnaire with the option for participants to complete an internet-based version. We opted for a short-format questionnaire (8 questions) with the goal of achieving a high response rate, accepting the trade-off of accumulating limited specific data (Supplemental File S1, https://figshare.com/articles/figure/ _/13526354). Questions were crafted using the fewest words necessary, using terms assumed to be understood by dairy farmers, and limited in scope to avoid the need for a respondent to seek other sources of information such as farm records. Multiple question types were used, including open "fill-in-the-blank" questions on number of lactating cows, years of farming experience, and breed(s) of cattle, and closed multiple-choice questions on winter housing type, bedding material use, and milk SCC testing frequency. A third option, "other, fill in the blank" was included for multiple-choice questions on housing and bedding types because we anticipated a possible range of responses beyond the categorical choices we provided.

The survey tool began with a statement informing participants of confidentiality and introduced the goals of the study and the URL of the web version of the survey (Supplemental File S2, https://figshare.com/ articles/figure/_/13526354). Personal identifiable information was limited to farm name and location. This information was included to identify and eliminate duplication of results across the 3 administration methods (e.g., if a farm completed both the mailed and internetbased versions). The assurance of confidentiality was reiterated at the end of the question section, just before a boxed section that asked for contact information for the farm. The questionnaire was pretested for clarity with members of the research team not involved in the initial question design and with the herd managers of the conventionally managed University of Vermont dairy research herd.

\section{Questionnaire Administration}

The survey tool was distributed through direct individual mailings and as an online version advertised through social media. The web-based questionnaire content was identical to the paper version and was created using Lime survey software (https://www .limesurvey.org/). The web-based questionnaire format was tested by research team members before opening for public access.

The web-based questionnaire went live on December 7, 2018, and was available until May 1, 2019. During the week following live access to the web-based questionnaire, the source population was informed of the study via announcements on University of Vermont Extension social media platforms and newsletters and through a press release sent to local newspapers, agriculturally focused web-based news outlets, stakeholder listservs, and organic association e-newsletters. Digitized announcements included a URL link to the web-based questionnaire.

The questionnaire, study goals description, and a separate stamped, self-addressed return envelope were first mailed on December 21, 2018, to the 197 farms in the USDA-OI database from the October 2018 search. A telephone call reminder was made the week of February 21,2019 , to farms that had not yet responded to either the mailed or web-based forms. Respondents who answered the call were given the opportunity to 
complete the questionnaire as a telephone interview; otherwise, if possible, a reminder message was left with a telephone number to call if the farmer preferred a telephone interview. After cross-referencing the updated USDA-OI database, a second mailing was distributed on March 6, 2019, to farms that had not yet responded (87 farms of the 177 in the December 2018 updated USDA-OI database). To eliminate duplicate contact attempts, identifying information (farm name) from completed questionnaires was used to identify nonresponding farms for each successive administration of the survey, but this private information was not included in any downstream analyses. The second mailing included an additional notice to apologize if the recipient had already completed the survey in another format and to prevent multiple submissions from the same farm.

\section{Analyses of Survey Responses}

Individual farms were identified by a numerical code, and questionnaire response data were separated from identifying information and digitally entered using Excel (Microsoft Corp.). Data from the web-based questionnaire were exported as a CSV file and merged into a single file with the mailed and telephone response data. The format for survey completion was recorded for each respondent, and occasional duplications (i.e., farms that responded by more than one method) were removed. Missing data for individual questions were identified and excluded from statistical analysis. All statistics were performed using R 4.0.2 software (https: //www.R-project.org/).

Descriptive summary statistics were calculated for each question. Calculation of $95 \%$ confidence intervals on reported proportions for types of housing and bedding systems and frequency of SCC testing was performed using the DescTools package (Signorell et al., 2020). Independence of categorical variables was assessed with Pearson's chi-squared test, or Fisher's exact test when count data included small numbers. Kruskal-Wallis rank sum test was used to test associations between ordinal dependent variables and independent variables with multiple categories, and when significant differences were observed the Dunn test for multiple comparisons with adjustment was applied using the FSA package (Ogle et al., 2020). Relationships between categorical independent variables with 2 or more levels and continuous dependent variables were assessed using 1-way ANOVA, and when a significant effect was observed, post hoc pairwise associations were tested using Tukey's procedure (TukeyHSD function). When extreme outlier observations were identified, the effect of removing outliers from the data was evaluated.
Tests of data normality and homogeneity of variance were performed, and where assumptions of normality appeared to be violated the data were transformed to approximate a normal distribution. Possible associations between SCC testing frequency category and independent predictors were tested by multinomial logistic regression. Because herd size and housing type were associated and were a priori identified as possible explanatory variables for SCC testing frequency, a multivariable model approach was used to investigate the relationship among housing, herd size, and SCC testing frequency. Because we were interested in whether herds used SCC testing at least monthly, the responses to the question on SCC testing frequency were reduced to a binary categorical variable [SCC testing less than (0) vs. greater than or equal to (1) approximately monthly] and entered as an outcome variable in binary logistic regression models. A forward stepwise variable selection process was used, and the final model was selected based on lowest Akaike information criteria, with final model fit assessed by plotting the deviance residuals. Goodness of fit for the final model was evaluated with the Hosmer-Lemeshow method. Wald test was used to evaluate the statistical significance of each predictor in the model. $P$-values were assigned to assess significance of association, with significance at $P \leq 0.05$.

\section{RESULTS AND DISCUSSION}

\section{Survey Methodology}

The overall response rate was $82 \%(\mathrm{n}=145)$ of 177 certified organic dairy farms producing cow milk in Vermont. Three producers reported via the first mailed survey that they were no longer active dairy producers, and 2 reported selling their herd when responding by phone (excluded from analysis). Four additional farms that were located outside of Vermont and were not included in the mailings responded to the web survey (excluded from analysis because they were not part of the source population). Based on the response to this survey, we suggest that the USDA-OI database is an acceptable source of contact information for research on organic dairy farms because it is publicly accessible, includes farm contact information, and is updated regularly using data submitted by organic farm certifiers.

The initial response to the web-based questionnaire was 26 farmers, $15 \%$ of the source population. Web responses were received between $\mathrm{d} 4$ and 45 of the 144-d live period of the survey. In contrast, the response to the first mailing was 75 participants, or $42 \%$ of the source population, within $75 \mathrm{~d}$ of the initial mailing. Telephone and mailed reminders accounted for 18 and 26 additional responses, respectively. 
The $82 \%$ response proportion for our survey far exceeds what has been reported previously for mailed questionnaires administered to farmers (Pennings et al., 2002; Pereira et al., 2013). For example, Pereira et al. (2013) obtained responses from $15 \%$ of the 1,200 members of the Northeast Organic Dairy Producers Alliance. Mailed questionnaires are most commonly used, at least partly due to cost and convenience advantages; however, their low response rate can be a barrier to obtaining a representative sample (Pennings et al., 2002). Potential factors that influence response to mail surveys among farmers include (1) timing of administration in the context of seasonal farm production schedules, (2) length of the questionnaire and perceived amount of time required to complete the mail survey, (3) potential compensation for participation, and (4) limiting questions to those that do not require farmers to consult records for factual information (Pennings et al., 2002). The recipient's interest in the topic of the questionnaire, the content of the cover letter introducing the study, the study's sponsors, and the stated goals of the study (including intended use of the data) also influence response, as does the use of follow-up reminders (Pennings et al., 2002). We suspected that the same factors may apply to farmer responses to questionnaires administered by other methods, such as internet or telephone, although in a review of the literature we were unable to find published research exploring these factors. Response frequency and timing appeared to differ among the administration methods, suggesting variation among organic dairy farmers in their proclivity to respond to different questionnaire administration methods, although our study was not designed to test this hypothesis. Further research seems warranted to explore dairy farmer preferences for questionnaire formats and administration methods and the effect of using multiple methods on survey response frequencies.

Additional factors that may have contributed to the high response frequency for this survey include relatively short length of the questionnaire and advertisement and administration of the survey in the "slower" winter season. Previous surveys of organic dairy farmers obtained responses in the range of 15 to $31 \%$ of the target population and did not report timing of survey administration relative to season of the year (Pereira et al., 2013; Stiglbauer et al., 2013; Sorge et al., 2016). Timeliness of the topic and interest to members of the source population, also known as "selection by the respondent," may have also been a factor contributing to our observed response (Pennings et al., 2002). Producer interest in the subject matter was measured by question $8 ; 98(68 \%)$ of the 145 respondents overall indicated they were "sorta" ( $\mathrm{n}=46)$ or "very" ( $\mathrm{n}=$ 52 ) interested in the survey results. Respondent interest was associated with the method of administration (Kruskal-Wallis $\chi^{2}=14.35 ; P<0.01$; Table 1 ). The proportion of respondents indicating "very" interested in the survey results was highest for those completing a web-based questionnaire, and pairwise comparisons indicated that the distribution of responses differed between web-based respondents and those who responded to the first and second mailings (adjusted $P=0.02$ and $<0.01$, respectively). This suggests that an interest in the study may have motivated web-based participation, although it is likely that other factors influenced the choice between completing a survey on the internet or by mail. Pereira et al. (2013) also administered a questionnaire to organic dairy farmers by both internetbased and print formats and did not appear to test an association between responses and questionnaire format. Neither years of dairy farm management experience nor total years of organic dairy farming experience were associated with method of survey response $(P=$ 0.73 and 0.74 , respectively).

Completion of $70 \%$ of web-based questionnaires occurred between December 10 and 13, 2019, when the first media communication went out, and December 21 and 23, 2019, when the first mailing was delivered. Although this suggests the importance of multiple reminders from varied media, no additional web-based participation occurred after the telephone reminder or second mailing, further supporting our speculation that web-based participation was related to interest level or timing of initial social media advertisements, among other factors. In contrast, respondents to the second mailing had the lowest proportion of "very" interested

Table 1. Frequency (\% in parentheses) of participant self-reported interest level in the survey results, stratified by the questionnaire administration method used by respondents

\begin{tabular}{lccccc}
\hline Interest level & First mailing & Second mailing & Phone & Web & Total \\
\hline Did not respond & $7(9.3)$ & $1(3.9)$ & $0(0)$ & $3(11.5)$ & $11(7.6)$ \\
Nope & $9(12.0)$ & $6(23.1)$ & $4(22.2)$ & $0(0)$ & $19(13.1)$ \\
Not really & $11(14.7)$ & $3(11.5)$ & $1(5.6)$ & $2(7.7)$ & $17(11.7)$ \\
Sorta & $24(32.0)$ & $13(50.0)$ & $3(16.6)$ & $6(23.1)$ & $46(31.7)$ \\
Very & $24(32.0)$ & $3(11.5)$ & $10(55.6)$ & $15(57.7)$ & $52(35.9)$ \\
Total & 75 & 26 & 18 & 26 & 145 \\
\hline
\end{tabular}


and a high proportion of no interest in survey results. Respondents interviewed by telephone also had a high level of interest ( $56 \%$ "very"). It is possible that webbased respondents would have also responded readily to the mail survey or telephone call had they not first filled out the web survey. Although response rates for internet-based questionnaires may be lower than those for mail-based surveys, when evaluated in a survey of American households, internet tools did not appear to exhibit item nonresponse bias (Hudson et al., 2004). In the context of our survey, the addition of an internetbased approach did not significantly increase the cost of our survey and had some advantages in terms of ease of data processing. We speculate that internet-based administration can be an effective option to supplement mailed questionnaires. Additional research is needed to determine whether internet-based questionnaires are a suitable mode of administration when used as the only option for farmer populations, especially given potential issues related to internet coverage in rural areas and possible self-selection bias related to demographic variables such as age (Hudson et al., 2004).

The short survey length may also have contributed to the high response rate. Conversely, the length was also a limitation, constraining the information collected by the survey, including why respondents demonstrated interest in this topic area. In retrospect, we believe that this issue is particularly interesting given that housing and bedding types were not identified as a research and education need in a previous survey of organic farmers in the northeastern United States (Pereira et al., 2013). Additional research would be necessary to understand the true motivation behind the high response rate. For example, were the respondents motivated by challenges they are experiencing with their current housing and bedding systems, or by perceived social trends or consumer demands related to confinement housing systems? Is any part of this farmer population considering alternative housing and bedding systems? As one farmer commented on the web-based survey, "I am very interested in the relationship between housing type, bedding type and pathogens.... I hope there will be [a] more in-depth survey at a later date."

\section{Survey Results}

Housing and Bedding Styles and Materials. All 145 respondents provided information on the type of facility used, whereas 1 respondent did not report the type of bedding used. A single type of housing system was used by 123 (85\%) respondents. The most common housing type for lactating cows on farms using a single housing system was tiestall $(\mathrm{n}=68,46 \%$; $95 \%$ CI: 39-55\%), which included 63 respondents (43\%; $95 \%$
CI: 36-53\%) using only wood products for bedding, 4 respondents using wood and hay or straw, and 1 respondent who did not report the bedding material used (Figure 1). Our results are consistent with a previous survey of 192 organic dairy farms in New York, Oregon, and Wisconsin, where $51 \%$ reported using tiestall or stanchion barns as a milking facility (Stiglbauer et al., 2013), and differ from a survey of 35 organic dairy herds in Minnesota, where $14 \%$ of farms reported using tiestalls as the primary housing during winter months (Sorge et al., 2016). In our survey, the next most frequent facility type on farms using single housing systems was freestall ( $\mathrm{n}=43,29 \%$; $95 \%$ CI: $21-38 \%$ ), which included 21 farms (14\%; 95\% CI: 10-21\%) bedding with only wood products and 18 farms (12\%; 95\% CI: 8-19\%) bedding with only sand (Figure 1). This is comparable with $34 \%$ of herds reporting using freestalls for housing during the winter months in Minnesota (Sorge et al., 2016). Use of a bedded pack system was reported on 22 farms (15\%; 95\% CI: 10-22\%). Of those using a bedded pack, 9 (6\%) farms reported using only a bedded pack housing system, and of these, 6 respondents used wood products for bedding and 3 used hay or straw for bedding (Figure 1). Loose housing with no stalls or cubicles (including bedded pack) was used solely or in combination with another housing type on $25(17 \%$; 95\% CI: $12-24 \%$ ) farms. Among the 22 farms that reported using a bedded pack for lactating cows, 13 used this strategy in conjunction with another lactating cow housing type ("bedded pack plus"; Figure 2), including tiestall or freestall housing, and the bedding types on these farms included wood products only $(\mathrm{n}=5)$; wood and hay or straw $(\mathrm{n}=5)$; hay or straw $(\mathrm{n}=2)$; and sand, wood products, and hay or straw $(\mathrm{n}=1)$. The remaining farms (14\%) reported a mixed tiestall and freestall system $(n=9)$, freestalls using both sand and wood $(\mathrm{n}=4)$, or a loose-housing system that was not described as a bedded pack and was bedded with wood products $(\mathrm{n}=3)$. In total, multiple housing systems for lactating cows were used on $22(15 \%)$ farms. This appears to differ from the herds surveyed in Minnesota, where 26\% used "mixed housing types" for lactating cows during winter months (Sorge et al., 2016). Another difference is that none of the respondents in our study reported using pasture as the primary housing during winter months, whereas in a prior survey 2 of 35 Minnesota herds reported continuously keeping lactating cows "on pasture" during the winter (Sorge et al., 2016). Because pasture was included as a choice for primary housing type in the survey of these 35 Minnesota farms, it is possible that many herds identified pasture plus another housing type and were included among the mixed housing category. In comparison, we did not include pasture as a primary housing category 


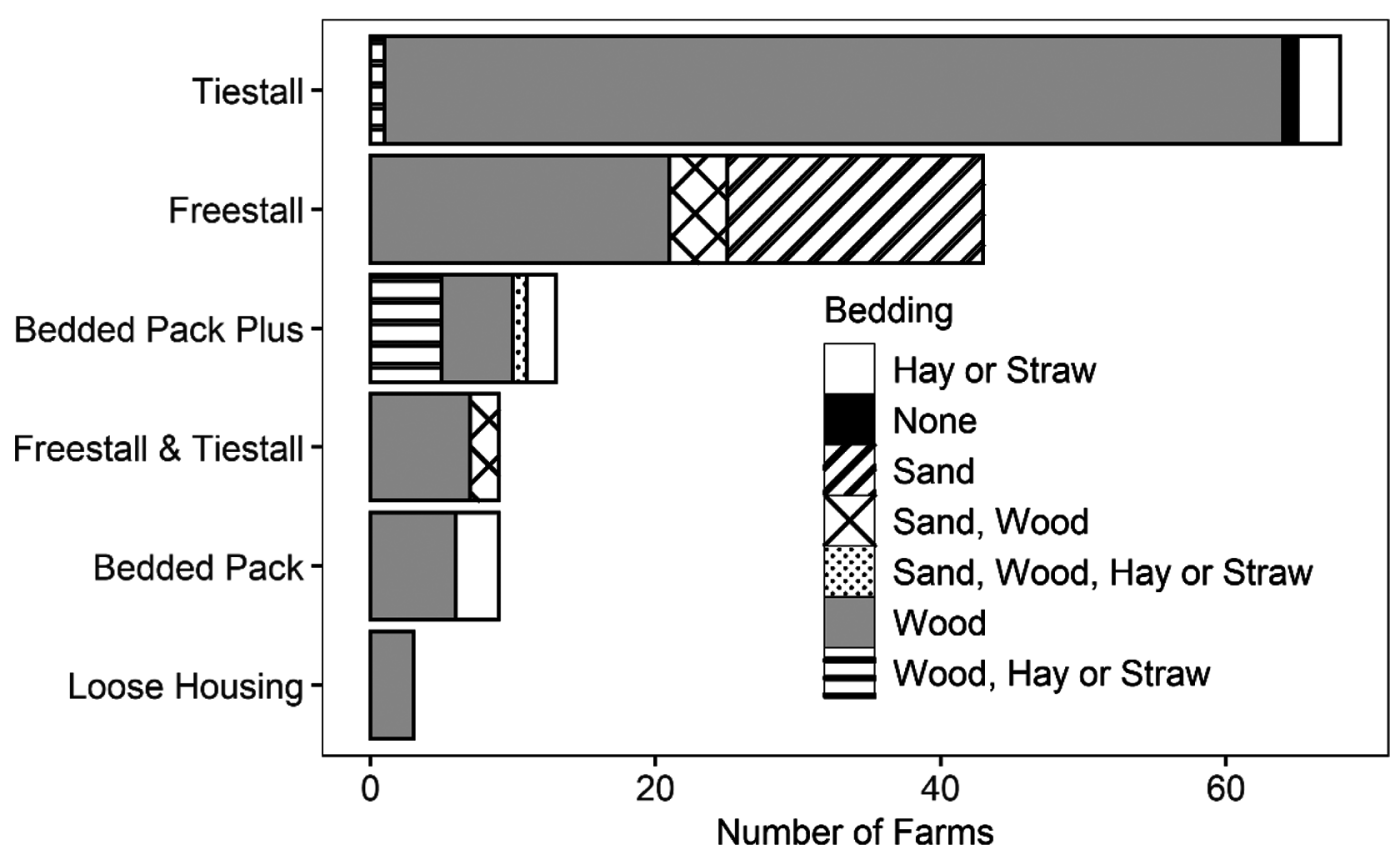

Figure 1. Number of farms within each housing strategy stratified by type of bedding material used (n = 144). Each stacked bar represents a different housing strategy, and pattern within bar represents the frequency of bedding material used within each strategy. Producers who reported using a bedded pack barn in combination with another housing type are grouped together ("bedded pack plus").

choice in our survey, although 6 of the 145 respondents included a comment that they provide outdoor access during winter months. The difference in wording of questions between our survey and other prior surveys of US organic dairy herds limits our ability to make comparisons.

There was a positive association between using more than one type of facility to house lactating cows and the number of lactating cows in respondent herds $(P$ $=0.03)$. We had not expected that so many respondents would use more than one type of facility and more than one type of bedding material. Herds using bedded packs had the most variation in bedding and housing types. "Mixed" housing systems using bedded packs in combination with another style were common. As discussed above, to encourage a high response rate, questions were designed to be brief and targeted, which restricted the information provided in responses. For example, because it is always constructed in an open floor plan barn, we chose to include "bedded pack" as a housing style rather than ask about loose housing and then clarify whether it was managed as a bedded pack.

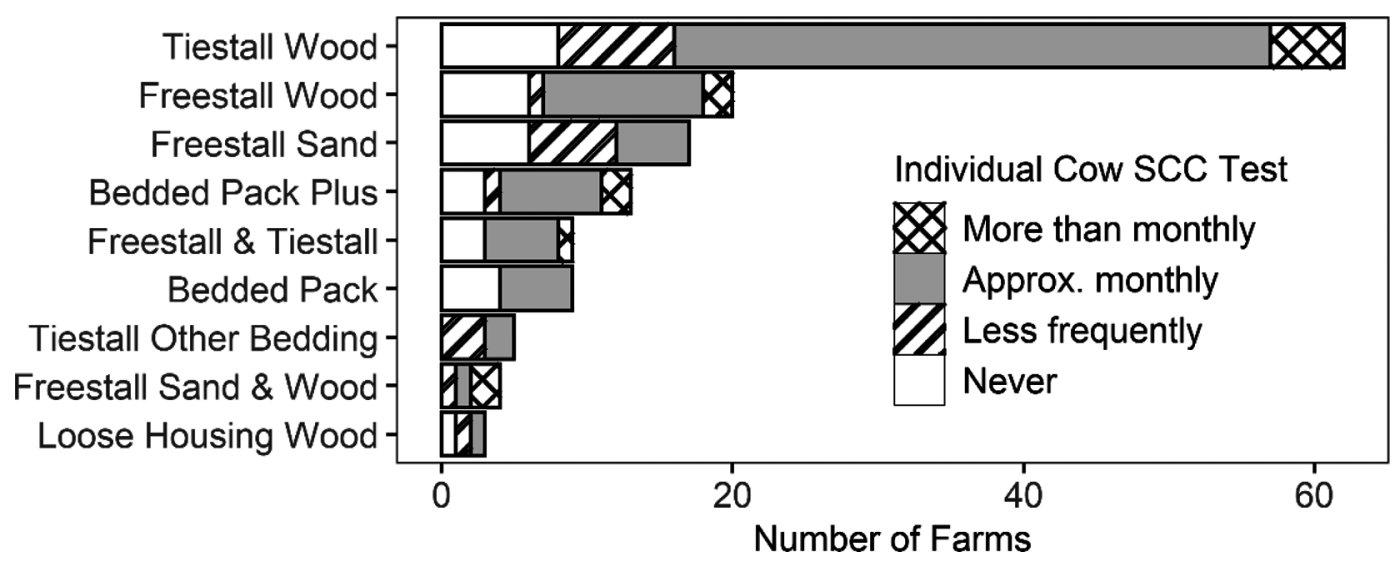

Figure 2. Frequency of SCC testing of individual cows in each housing and bedding strategy. Each stacked bar represents a different combination of housing strategy and bedding material. Pattern within bar represents frequency of SCC determinations on individual cows $(\mathrm{n}=144)$. 
Furthermore, although respondents were able to select more than one bedding or housing type, there was an open component to this question where respondents could write a short response specifying which bedding was associated with which housing type. Although this had the effect of shortening the survey, it may have introduced some potential measurement error. No respondent who selected multiple housing and bedding strategies was specific about which bedding was used in each housing type, highlighting a limitation of the current survey method and format. Future surveys could incorporate alternative methods (e.g., interview questionnaires) or questionnaire designs that allow respondents to provide more detailed information.

Survey administration type was associated with housing and bedding system $\left(\chi^{2}=21.68, P=0.04\right)$. Producers using bedded pack and freestall wood systems were the most common users of the web-based survey (32 and 43\%, respectively) relative to all other housing bedding types (average 12\% among all categories). Correspondingly, producers using bedded pack or freestall wood systems responded with high level of interest (91 and 88\% for "very" and "sorta" interested, respectively). We speculate that these associations reflect interest level in the survey information due to either dissatisfaction with current housing and bedding systems or enthusiasm and interest in the survey information (i.e., evoked reciprocation influence; Groves, 1990). In contrast, producers using a freestall bedded with sand exhibited the greatest "nope" (not interested) and least "very" interested, and this group did not show a preference for survey administration types. This apparent lack of interest suggests that this group of farmers is most satisfied with their current housing and bedding system and is not looking for additional information. These observations highlight the opportunity to develop studies to test hypotheses that mode of questionnaire administration, producer interest in topics related to cattle housing, and producer satisfaction with current bedding systems influence survey response rate across the range management styles.

Cattle Breeds. We grouped breed types reported by respondents into 4 categories: (1) Holstein only (n $=36)$, (2) Jersey only $(\mathrm{n}=29)$, (3) mixed Holstein or Jersey herds with crosses $(\mathrm{n}=36)$, or (4) mixed Jersey and Holstein herds with 1 or more additional breeds $(\mathrm{n}=25)$. Sixteen herds reported other breeds that did not fit these categories (Ayrshire, Brown Swiss, Guernsey, Lineback, Milking Shorthorn, and Normande). Our finding of the frequent use of crossbreeds or breeds other than Holstein cattle on organic farms is consistent with previous surveys (Stiglbauer et al., 2013; Sorge et al., 2016). Three respondents did not report the breed(s) of cattle on their farm, leaving
142 responses included in analysis of breed associations with facility and bedding types. While breed distribution was similar across the housing and bedding type combination categories (Fisher's exact test, $P=0.26$ ), 5 of $9(55 \%)$ producers using only bedded pack-style housing reported using Jerseys and Jersey crosses compared with the next highest proportion of Jersey or Jersey cross herds among tiestall farms $(\mathrm{n}=19,30 \%)$ and freestall farms $(\mathrm{n}=8,22 \%)$.

Frequency of Individual Cow SCC Testing. Frequency of testing SCC for individual cows was reported by 142 respondents; 3 respondents did not report SCC testing frequency on their farm and were excluded from analysis of associations between SCC testing and facility or bedding types. Twelve farmers reported testing SCC for individual cows more than 12 times per year, 78 farmers reported SCC testing approximately monthly, 21 farmers reported SCC testing less than 6 times per year, and 31 farmers reported never using SCC testing (Figure 2). In previous surveys, $69 \%$ of 35 organic dairy farms in Minnesota (Sorge et al., 2016) and $53 \%$ of 192 organic dairy farms in New York, Oregon, and Wisconsin (Stiglbauer et al., 2013) reported using DHIA services, although neither study appeared to explore how organic dairy farmers use DHIA testing data, frequency of SCC testing, or whether SCC testing frequency was associated with other management practices. In this study, we found an association between housing type and SCC testing frequency $(P$ $=0.02$ ). Producers using freestall sand facilities were less likely to test approximately monthly or greater compared with those using tiestalls with wood bedding $(P=0.01)$. Number of lactating cows (herd size) was not associated with any SCC testing frequency category $(P>0.54$ in a univariable model and $P>$ 0.16 in the multivariable model that included housing type), and inclusion of both housing type and herd size did not improve the overall fit of the model compared with the model with only housing type. We note that 4 of the 9 bedded pack herds reported never using SCC testing. The relatively small number of farmers in the bedded pack category compared with the size of the other categories (17 freestall sand, 20 freestall wood, 62 tiestall wood, and 34 other) creates the potential to falsely conclude that there is no difference between this group and the others when a difference actually exists. Future studies testing associations between housing or bedding types that include bedded pack herds should account for the observation that use of this housing type appears to be relatively infrequent compared with use of other systems.

Our estimate of individual cow SCC testing frequency appears to be similar to the frequency of DHIA testing reported previously (Stiglbauer et al., 2013; Sorge et al., 
2016); however, the accuracy of our results may have been restricted and possibly underestimated due to the wording of our survey question. For example, when asking about individual cow SCC testing, we provided an acronym, DHIA, commonly associated with a regular testing service that can include individual cow milk SCC measurement by flow cytometry because we were specifically interested in this form of SCC testing. We expect that farmers interpreted this to mean we were asking about subscription to a regular testing service that includes SCC testing. For example, one producer reported never performing individual cow SCC tests but then noted in a comment that the California mastitis test was used for testing individual cows on their farm, suggesting that this farmer recognized the difference in these different mastitis screening tests. Previous questionnaires were administered as interviews and separated questions on subscriptions to monthly animal production record-keeping services from questions on methods for identifying subclinical mastitis (Stiglbauer et al., 2013; Sorge et al., 2016). Routine California mastitis test or cow-side SCC testing has been reported to be used more frequently than DHIA testing on organic dairy herds in other US states, although DHIA use was defined as full service including milk quality, breeding, production, calving, and herd inventory information (Stiglbauer et al., 2013). Further research is needed to quantify mastitis screening practices in this target population.

Number of Lactating Cows. One respondent did not report the number of lactating cattle on their farm; 144 respondents were included in analysis of herd size associations with facility and bedding types. The median lactating cow herd size was 59.5 cows (range: 2-400; mean: 71; SD: 4.5; 95\% CI: $62-80$ cows; Figure $3)$. The number of lactating cows reported by respondents was in the range reported by other surveys of US organic dairy farms (Sorge et al., 2016). The number of cows varied between housing bedding types in this study population $(P<0.01)$; past surveys of US organic dairy farms did not appear to explore this association (Stiglbauer et al., 2013, 2017). Producers reporting using freestall systems bedded with sand and wood or using both freestalls and tiestalls housed more cows than producers reporting using tiestalls $(P<0.05$ in post hoc pairwise comparisons). When extreme outliers were removed from the categories bedded pack plus, freestall with sand, freestall and tiestall, and freestall with wood, the confidence in these associations was improved $(P<0.01)$. Despite these differences, many producers using freestall barns had a herd size that was similar to all other housing types (Figure 3). Other studies investigated herd size, facility age, or facility type on organic dairy farms but not within the same survey. For example, Sorge et al. (2016) reported a 10yr mean change in herd size of 5.7 cows (range: -11 to +30 ) but did not report on associated changes in facility types, whereas Stiglbauer et al. (2013) reported the mean age of housing ( $36.5 \mathrm{yr}$ ) but did not report changes in herd size or facility types for US organic farms. Future surveys might collect more detailed data on farms that use multiple housing and bedding types as well as trends in facility types and herd size for organic dairy farms.

Years of Dairy Farming Experience. Years of experience could be perceived as a variable in stud-

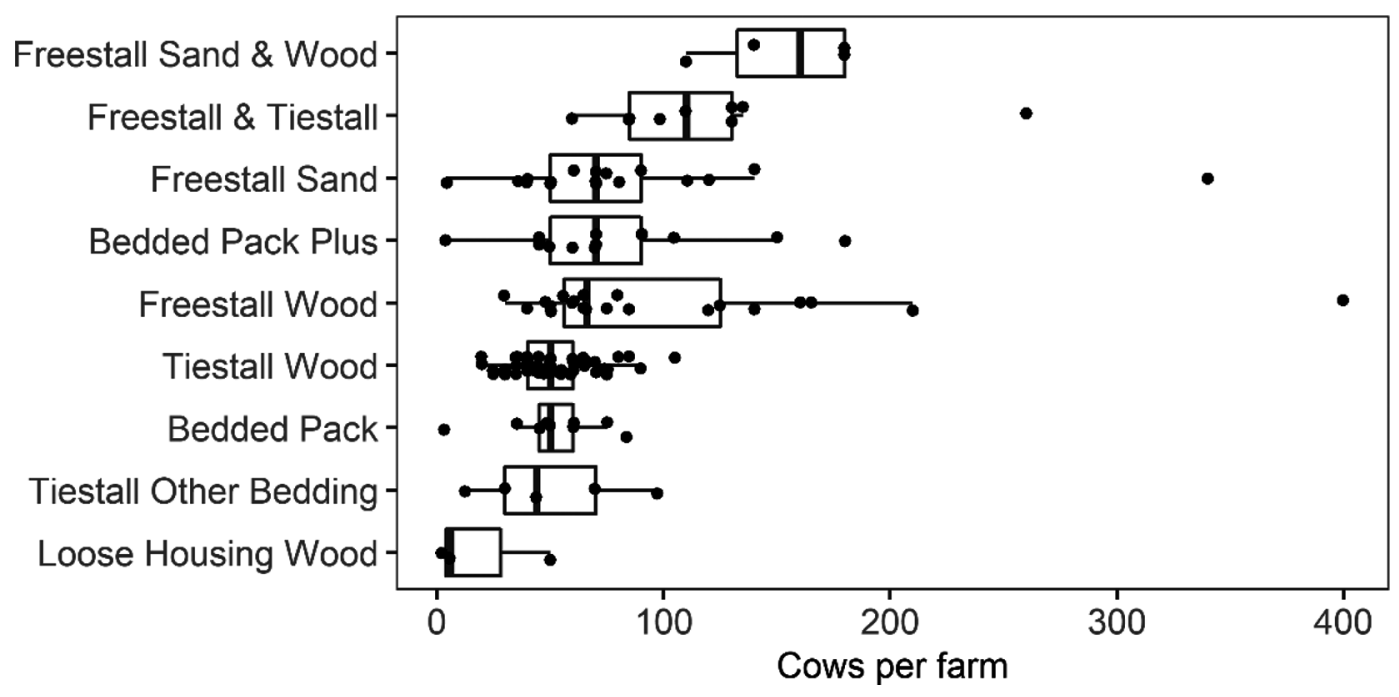

Figure 3. Number of cows varied among housing and bedding types. Illustrated is a box plot with the center line as the median $(\mathrm{n}=144)$. Points represent individual farm herd size; box represents interquartile range (IQR, 25th to 75 th percentiles); whiskers represent $1.5 \times$ IQR. 


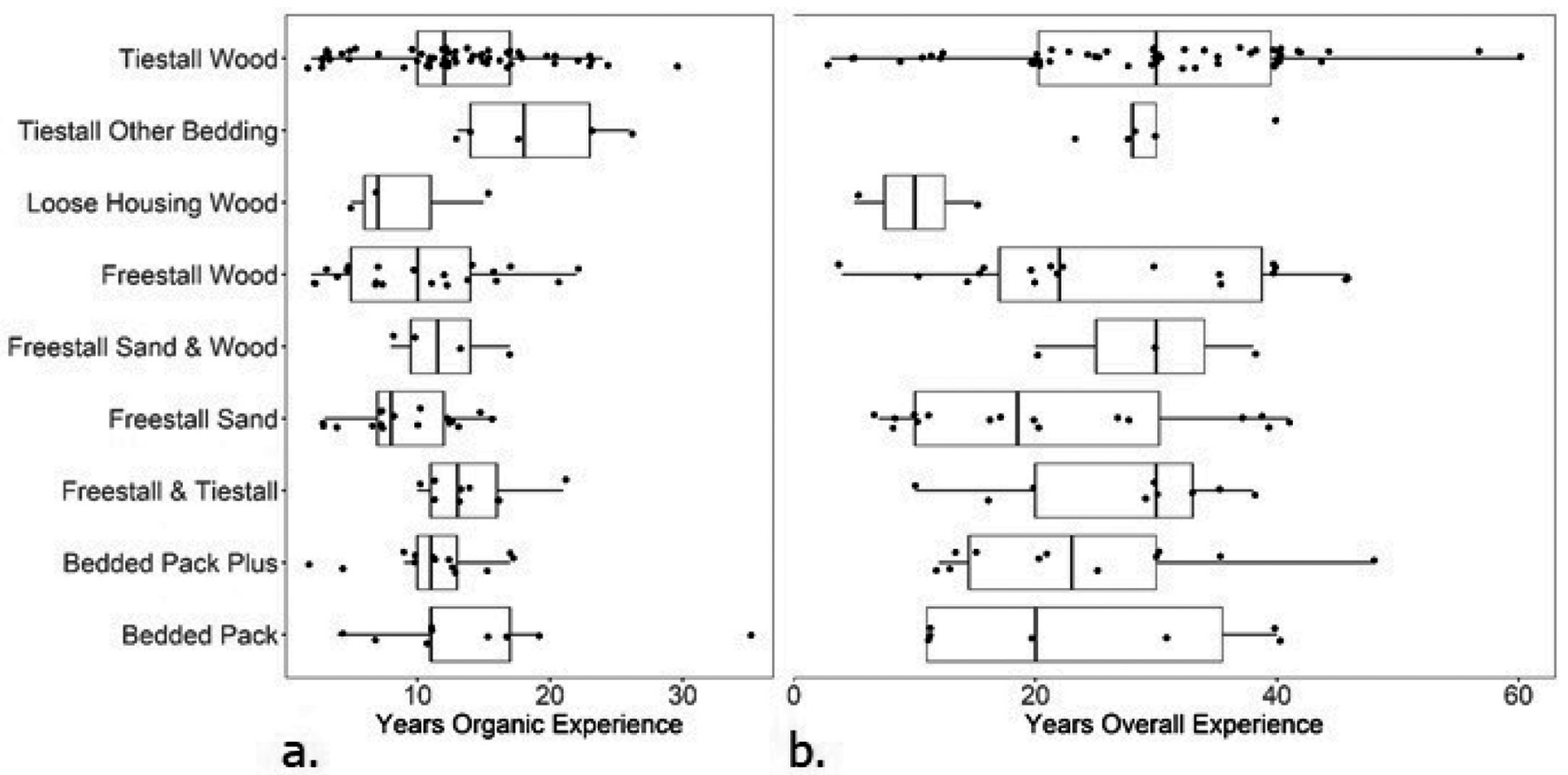

Figure 4. Distribution of management experience in each housing and bedding strategy. Illustrated is a box plot with a median center line for years of $(\mathrm{a})$ organic dairy experience $(\mathrm{n}=144)$ and $(\mathrm{b})$ total dairy experience $(\mathrm{n}=126)$; box represents interquartile range (IQR, 25th to 75th percentiles); whiskers represent $1.5 \times \mathrm{IQR}$.

ies measuring the effect of management. Total years of dairy farm management experience for any farm type was reported by 126 respondents; however, 144 respondents reported years of organic dairy farm management experience. Respondents' overall years of dairy experience was not associated with housing or bedding category $(P=0.20$; Figure 4$)$. The years of organic dairy farm experience had a narrower range than length of the total dairy experience, we suspect because many producers transitioned to organic from conventional dairy management.

\section{Future Housing Trends and Research Priorities for Organic Dairy Farms}

In the United States, producers of organic ruminant livestock must provide year-round access to the outdoors. Farmers may provide temporary confinement or shelter for animals because of inclement weather and animal health, safety, and well-being, among other reasons. Shelter or housing for US organic dairy cattle must be designed to allow for "(i) natural maintenance, comfort behaviors, and opportunity to exercise; (ii) temperature level, ventilation, and air circulation suitable to the species; and (iii) reduction of potential for livestock injury" (USDA, 2020). In our review of the literature, we found that research on shelter or hous- ing for US organic dairy herds is limited. We propose that continued research on the effect of housing and bedding on organic dairy cattle productivity and wellbeing, including animal health (e.g., lameness and mastitis), would inform best practices regionally and nationally, especially for regions where indoor winter housing facilities and bedding materials may be used for 5 to 6 mo of the year. Our survey improves knowledge of lactating cow housing and bedding types used on organic dairy farms in Vermont and identifies some key issues for further study. In particular, given the relatively high frequency of tiestall housing facilities in this sample, research is needed on how organic dairy producers perceive and are responding to changing consumer demands related to confinement housing.

Better knowledge of the distribution and types of housing and bedding used on organic dairy farms is necessary to identify representative samples for research studies. Research on the relationship between housing types and animal behavior, health, and well-being and environmental impacts is important to help direct the future of housing for dairy cattle and could help inform consumer acceptance of common cattle husbandry systems. For example, a picture-based approach used to assess the public acceptance of common indoor housing systems in Germany found that the acceptance of loose housing (freestall barns) was relatively low (17\% 
or less) and paddock or pasture access increased public acceptance (Kühl et al., 2019). Notably, their study did not include an assessment of consumer acceptance of either confinement tiestall barns with pasture access during good weather (i.e., the most common scenario among respondents in our sample population of organic dairy farms) or loose-housing bedded pack systems with pasture access during good weather (Leso et al., 2020). We suggest that understanding the potential benefits of and barriers to transitioning pasture-based or organic dairy farms from tiestall confinement facilities to alternative housing is a critical research need in Vermont, regionally in the northeast US, nationally, and perhaps globally.

Bedded pack, compost bedded pack, or loose-housing systems are designed for cow comfort and may offer several advantages over other housing systems (Astiz et al., 2014; Leso et al., 2020). Fewer foot and leg injuries are cited in loose-housing bedded pack or compost bedded pack systems compared with freestall barns (Lobeck et al., 2011; Burgstaller et al., 2016). There are reports of decreased incidence of mastitis for dairy cows housed on compost bedded pack (Astiz et al., 2014). Although Black et al. (2014) suggested mastitis-causing bacterial genera are found in high concentrations in composted bedded pack systems, among Kentucky dairy farms selected based on SCC history as a proxy for "good management," udder health and hygiene on composted bedded pack herds was comparable with that on sandbedded freestalls (Eckelkamp et al., 2016). In other regions, potential differences between freestall, tiestall, and compost bedded pack facilities are less clear for animal health and productivity outcomes such as hygiene, mastitis, and milk production and quality (Leso et al., 2020). All animal welfare, health, and productivity measures appear to be influenced by the type of bedding material used in addition to the type of facility (Leso et al., 2020). Bedded pack compost material is a highly suitable soil amendment that can increase soil organic matter and fertility, providing an additional benefit to the farm system (Leso et al., 2020). Despite these potential benefits, our survey results indicate that the adoption of compost bedded packs for lactating cows on organic dairy farms in Vermont is relatively limited and, when used as the only bedding system for lactating cows, was less frequent than we had predicted before this survey. One recent study found improved hygiene and udder health for cows housed outdoors ("outwintered") on straw bedded packs compared with cows housed indoors on compost bedded pack during 3 winters in Minnesota (Sjostrom et al., 2019). In our survey, only 1 farm reported primarily using outdoor housing for lactating cows and returning cows to tiestalls only during inclement weather, although 6 respondents commented that cows had daily outdoor access. Similar to the past surveys, we did not ask about frequency of outdoor access during nongrazing winter months (Stiglbauer et al., 2013; Sorge et al., 2016). Future studies of winter housing for organic dairy cattle should include methods to quantify the extent of outdoor access relative to housing use and daily weather conditions as factors that influence production, health, and well-being outcomes.

\section{CONCLUSIONS}

Our survey found that tiestall barns bedded with wood products are the dominant winter housing system for lactating organic dairy cattle in Vermont. We identified a diversity of housing systems, including several farms using mixed housing and bedding types in organic dairy production in Vermont. A relatively small number of organic farmers reported using bedded packs in open-housing systems for lactating cows. We conclude that developing a simple survey and timing the survey for the optimal availability of the target farmer population can result in a high response. Interest in the topic of housing and bedding also appeared to influence response. Future research should leverage this interest to foster key relationships with organic producers to build a more robust research and extension program supporting housing and facilities management. The approach presented here might be adapted in other regions to survey farmers in organic dairy production.

\section{ACKNOWLEDGMENTS}

We thank Jennifer Colby and Juan Alvez for assistance with identifying organic herd mailing lists and developing and promoting the survey through extension and industry mailing lists, and Cheryl Herrick and Colene Reed for their administrative support [University of Vermont (UVM) Center for Sustainable Agriculture]. Jennifer Colby and Alissa White (UVM Extension and the Gund Institute for the Environment) provided much-appreciated advice on questionnaire design and administration methods. Funding for this research was provided by the USDA-NIFA (Washington, DC) Organic Research and Extension Initiative competitive grant \#2018-51300-28561. The authors declare no conflict of interest related to design, conduct, or reporting of this research.

\section{REFERENCES}

Astiz, S., F. Sebastian, O. Fargas, M. Fernandez, and E. Calvet. 2014. Enhanced udder health and milk yield of dairy cattle on compost bedding systems during the dry period: A comparative study. Livest. Sci. 159:161-164. https://doi.org/10.1016/j.livsci.2013.10.028. 
Beaver, A., K. L. Proudfoot, and M. A. G. von Keyserlingk. 2020. Symposium review: Considerations for the future of dairy cattle housing: An animal welfare perspective. J. Dairy Sci. 103:57465758. https://doi.org/10.3168/jds.2019-17804.

Bewley, J. M., L. M. Robertson, and E. A. Eckelkamp. 2017. A 100year review: Lactating dairy cattle housing management. J. Dairy Sci. 100:10418-10431. https://doi.org/10.3168/jds.2017-13251.

Bewley, J. M., J. L. Taraba, G. B. Day, R. Black, and F. A. Damasceno. 2012. Compost Bedded Pack Barn Design: Features and Management Considerations. University of Kentucky Cooperative Extension Publication ID-206. Accessed May 23, 2020. http:// www2.ca.uky.edu/agcomm/pubs/id/id206/id206.pdf.

Black, R. A., J. L. Taraba, G. B. Day, F. A. Damasceno, M. C. Newman, K. A. Akers, C. L. Wood, K. J. McQuerry, and J. M. Bewley. 2014. The relationship between compost bedded pack performance, management, and bacterial counts. J. Dairy Sci. 97:2669-2679. https://doi.org/10.3168/jds.2013-6779.

Bothfeld, D. 2020. Vermont Dairy Data-July 15, 2019. Accessed Oct. 25, 2020. https://legislature.vermont.gov/Documents/ 2020/WorkGroups/Senate\%20Agriculture/Reports\%20and\%20 Resources/W Diane\%20Bothfeld $\sim$ Vermont\%20Dairy\%20Data 7 -15-2019.pdf

Burgstaller, J., J. Raith, S. Kuchling, V. Mandl, A. Hund, and J. Kofler. 2016. Claw health and prevalence of lameness in cows from compost bedded and cubicle freestall dairy barns in Austria. Vet. J. 216:81-86. https://doi.org/10.1016/j.tvj1.2016.07.006.

Eckelkamp, E. A., J. L. Taraba, K. A. Akers, R. J. Harmon, and J. M. Bewley. 2016. Sand bedded freestall and compost bedded pack effects on cow hygiene, locomotion, and mastitis indicators. Livest. Sci. 190:48-57. https://doi.org/10.1016/j.livsci.2016.06.004.

Endres, M. I., and K. A. Janni. 2019. Compost Bedded Pack Barns for Dairy Cows. Accessed May 23, 2020. https://dairy-cattle.extension .org/compost-bedded-pack-barns-for-dairy-cows/.

Gilker, R. E., J. E. Bakelaar, M. P. Cannella, and D. A. Neher. 2012. Bedded Pack in Vermont: Five Stories. Accessed May 23, 2020. https://www.uvm.edu/sites/default/files/media/508 _beddedpackwebversionfinal.pdf.

Groves, R. M. 1990. Theories and methods of telephone surveys. Annu. Rev. Sociol. 16:221-240. https://doi.org/10.1146/annurev .so.16.080190.001253.

Hudson, D., L.-H. Seah, D. Hite, and T. Haab. 2004. Telephone presurveys, self-selection, and non-response bias to mail and Internet surveys in economic research. Appl. Econ. Lett. 11:237-240. https: //doi.org/10.1080/13504850410001674876.

Kühl, S., S. Gauly, and A. Spiller. 2019. Analyzing public acceptance of four common husbandry systems for dairy cattle using a picture-based approach. Livest. Sci. 220:196-204. https://doi.org/10 .1016/j.livsci.2018.12.022.

Leso, L., M. Barbari, M. A. Lopes, F. A. Damasceno, P. Galama, J. L. Taraba, and A. Kuipers. 2020. Invited review: Compost-bedded pack barns for dairy cows. J. Dairy Sci. 103:1072-1099. https://doi .org/10.3168/jds.2019-16864.

Lobeck, K. M., M. I. Endres, E. M. Shane, S. M. Godden, and J. Fetrow. 2011. Animal welfare in cross-ventilated, compost-bedded pack, and naturally ventilated dairy barns in the upper Midwest. J. Dairy Sci. 94:5469-5479. https://doi.org/10.3168/jds.2011-4363.

O'Connor, A. M., J. M. Sargeant, I. R. Dohoo, H. N. Erb, M. Cevallos, M. Egger, A. K. Ersbøll, S. W. Martin, L. R. Nielsen, D. L. Pearl, D. U. Pfeiffer, J. Sanchez, M. E. Torrence, H. Vigre, C. Waldner, and M. P. Ward. 2016. Explanation and elaboration document for the STROBE-Vet statement: Strengthening the Reporting of Observational Studies in Epidemiology-Veterinary Extension. Zoonoses Public Health 63:662-698. https://doi.org/10.1111/zph.12315.
O'Hara, J. K., and R. L. Parsons. 2013. The economic value of organic dairy farms in Vermont and Minnesota. J. Dairy Sci. 96:61176126. https://doi.org/10.3168/jds.2013-6662.

Ogejo, J. A. 2018. Compost Bedded Pack Dairy Barns. Virginia Cooperative Extension Publication 442-124. Accessed May 23, 2020. https://vtechworks.lib.vt.edu/bitstream/handle/10919/84284/ BSE-228.pdf?sequence $=1 \&$ is Allowed $=\mathrm{y}$.

Ogle, D. H., P. Wheeler, and A. Dinno. 2020. FSA: Fisheries Stock Analysis. R package version 0.8.30. Accessed Aug. 14, 2020. https: //github.com/droglenc/FSA.

Pennings, J. M. E., S. H. Irwin, and D. L. Good. 2002. Surveying farmers: A case study. Rev. Agric. Econ. 24:266-277. https://doi.org/ 10.1111/1467-9353.00096.

Pereira, A. B., A. F. Brito, L. L. Townson, and D. H. Townson. 2013. Assessing the research and education needs of the organic dairy industry in the northeastern United States. J. Dairy Sci. 96:73407348. https://doi.org/10.3168/jds.2013-6690.

Richert, R. M., K. M. Cicconi, M. J. Gamroth, Y. H. Schukken, K. E. Stiglbauer, and P. L. Ruegg. 2013. Risk factors for clinical mastitis, ketosis, and pneumonia in dairy cattle on organic and small conventional farms in the United States. J. Dairy Sci. 96:42694285. https://doi.org/10.3168/jds.2012-5980.

Signorell, A., K. Aho, A. Alfons, et al. 2020. DescTools: Tools for Descriptive Statistics. R package version 0.99.38. Accessed Aug. 14, 2020. https://cran.r-project.org/package=DescTools.

Sjostrom, L. S., B. J. Heins, M. I. Endres, R. D. Moon, and U. S. Sorge. 2019. Effects of winter housing system on hygiene, udder health, frostbite, and rumination of dairy cows. J. Dairy Sci 102:10606-10615. https://doi.org/10.3168/jds.2018-15759.

Sorge, U. S., R. Moon, L. J. Wolff, L. Michels, S. Schroth, D. F. Kelton, and B. Heins. 2016. Management practices on organic and conventional dairy herds in Minnesota. J. Dairy Sci. 99:3183-3192. https://doi.org/10.3168/jds.2015-10193.

Stiglbauer, K. E., K. M. Cicconi-Hogan, R. Richert, Y. H. Schukken, P. L. Ruegg, and M. Gamroth. 2013. Assessment of herd management on organic and conventional dairy farms in the United States. J. Dairy Sci. 96:1290-1300. https://doi.org/10.3168/jds .2012-5845.

USDA. 2010. Dairy 2007: Facility Characteristics and Cow Comfort on U.S. Dairy Operations, 2007. Accessed Aug. 25, 2020. https: //www.aphis.usda.gov/animal_health/nahms/dairy/downloads/ dairy07/Dairy07_ir_Facilities_1.pdf.

USDA. 2016. Dairy 2014: Dairy Cattle Management Practices in the United States, 2014. Accessed Jul. 21, 2020. https://www.aphis .usda.gov/animal_health/nahms/dairy/downloads/dairy14/ Dairy14_dr_PartI_1.pdf.

USDA. 2020. National Organic Program (NOP) Organic Rules and Regulations. Accessed Jul. 23, 2020. https://www.ams.usda.gov/ rules-regulations/organic.

USDA-NASS. 2017. Certified Organic Survey 2016 Summary. Accessed May 23, 2020. https://www.nass.usda.gov/Surveys/Guide _to_NASS_Surveys/Organic_Production/index.pp.

\section{ORCIDS}

Tucker Andrews @ $\odot$ https://orcid.org/0000-0001-9312-6478 Caitlin E. Jeffrey ํㅏ https://orcid.org/0000-0002-7121-5493 Rachel E. Gilker ๑ https://orcid.org/0000-0001-7145-741X Deborah A. Neher ๑ https://orcid.org/0000-0002-9647-8783 John W. Barlow () https://orcid.org/0000-0002-7815-9383 